\title{
Preparation and characterization of $\mathrm{Eu}^{3+}$ activated $\mathrm{CaSiO}_{3},(\mathrm{CaA}) \mathrm{SiO}_{3}$ $[\mathrm{A}=\mathrm{Ba}$ or Sr] phosphors
}

\author{
S J DHOBLE*, N S DHOBLE ${ }^{\dagger}$ and R B PODE \\ Kamla Nehru College, Sakkardara Square, Nagpur 440 009, India \\ †Sevadal Women's College, Sakkardara Square, Nagpur 440 009, India \\ ${ }^{+}$Department of Physics, Nagpur University, Nagpur 440 010, India
}

MS received 27 December 1999; revised 4 March 2003

\begin{abstract}
Eu}^{3+}$ activated $\mathrm{CaSiO}_{3},(\mathrm{Ca}, \mathrm{Ba}) \mathrm{SiO}_{3}$ and $(\mathrm{Ca}, \mathrm{Sr}) \mathrm{SiO}_{3}$ have been prepared by sol-gel technique. Residual solvent and organic contents in the gel were removed by firing at $100^{\circ} \mathrm{C}$ for $3-4 \mathrm{~h}$ at 300 and $600^{\circ} \mathrm{C}$ for $2 \mathrm{~h}$. Small exothermic shoulder around 850 to $875^{\circ} \mathrm{C}$, as observed in DTA curve, corresponds to crystallization temperature of the doped calcium silicate. Influence of firing temperature on the luminescence of $\mathrm{Eu}^{3+}$ shows the maximum emission intensity in gel fired at $850^{\circ} \mathrm{C}$. Photoluminescence emission peak is observed at $614 \mathrm{~nm}$ due to ${ }^{5} D_{0} \rightarrow{ }^{7} F_{2}$ transition of $\mathrm{Eu}^{3+}$ ion in $(\mathrm{Ca}, \mathrm{Ba}) \mathrm{SiO}_{3}$ and $(\mathrm{Ca}, \mathrm{Sr}) \mathrm{SiO}_{3}$ phosphors, when excited by $254 \mathrm{~nm}$. The (Ca, Ba) $\mathrm{SiO}_{3}$ material is proposed as an efficient red phosphor.
\end{abstract}

Keywords. $\mathrm{CaSiO}_{3}$; photoluminescence; sol-gel; phosphor.

\section{Introduction}

Oxides, silicates, phosphates, borates and fluorides doped with rare earth ions have received great attention because of their potential applications in optical and laser devices. Koedam and Opstelten (1971) predicted a tri-colour lamp and development of lamp phosphors. Later on, Haft and Thornton (1972) developed the tri-colour lamp based on predictions. Theoretically it is predicted that good colour rendering index (CRI) can be obtained if three emission bands centred around $450 \mathrm{~nm}$ (blue), $540 \mathrm{~nm}$ (green) and $610 \mathrm{~nm}$ (red) are combined. Haft and Thornton used $\mathrm{Y}_{2} \mathrm{O}_{3}: \mathrm{Eu}^{3+}$ for red, $\mathrm{Eu}^{2+}$ doped strontium chlorapatite for blue and $\mathrm{Mn}$ doped zinc silicate for green emissions. Rare earth ions are known to exist in various valence states although the trivalent state is the most prevalent. Particularly Sm and Eu ions are known to be stable in trivalent as well as in divalent states. Photoluminescence (PL) of europium has been extensively studied in different hosts (Ohnishi 1983; Welker 1991; Upadeo and Moharil 1996; Otvos and Peto 1998; Band et al 1999). $\mathrm{Eu}^{3+}$ exhibits a red or orange luminescence, while $\mathrm{Eu}^{2+}$ strongly depends on the host and it may emit anywhere from UV to deep red region. Luminescence of $\mathrm{Eu}^{3+}$ has been used to obtain the red component of the full colour display devices (Raue et al 1984; Smets 1987; Leskela and Niinitso 1992). The $\mathrm{Eu}^{3+}$ activated oxides have been extensively investigated due to their applications as red lamp phosphors (Wanmaker et al 1966; Blasse 1970).

*Author for correspondence
Recently, we have published $\mathrm{Eu}^{3+}$ activated $\mathrm{CaWO}_{4}$ (Pode and Dhoble 1997) and $\mathrm{A}-\mathrm{BaGd}\left(\mathrm{PO}_{4}\right)_{2}(\mathrm{~A}=\mathrm{Li}, \mathrm{Na}$ or K) (Band et al 1999) as red phosphors. $\mathrm{Eu}^{2+}$ has been extensively used in obtaining the blue component of lamp phosphors (Smets 1987), colour TV (Welker 1991), Xray imaging phosphors (Wanmaker and ter Vrugt 1967; Meijerink and Blasse 1989; Crawford and Bixner 1991; Moharil 1994), in lamps for photocopying (Wanmaker and ter Vrugt 1967) etc. In recent years, Mn activated $\mathrm{Zn}_{2} \mathrm{SiO}_{4}$ has been found to be suitable for many more applications such as thin film electroluminescent devices (Ouyang et al 1996), plasma display panels (Cich et al 1998; Sohn et al 2000), medical imaging detector for low voltage radiography as well as fluoroscopy (Kandarakis et al 1998; Cavouras et al 2000). Silicates doped with rare earth ions have received great attention because of their potential applications in optical and laser devices. $\mathrm{CaSiO}_{3}$ has been used as a raw material of tile and pottery (Kurczyk and Wuhrer 1971), a filler to resin (Jain et al 1992). $\mathrm{X}_{2-} \mathrm{Y}_{2} \mathrm{SiO}_{5}: \mathrm{Tb}^{3+}$ is one of the best green emitting cathodoluminescence phosphors (Peters 1969; Rabinovich et al 1987) and $\mathrm{X}_{2}-\mathrm{Y}_{2} \mathrm{SiO}_{5}: \mathrm{Ce}^{3+}$ is a good blue phosphor (Gomes and Bril 1969a,b). In most of the studies solid state diffusion technique has been used for the synthesis. In recent years, novel methods such as polymer pyrolysis (Su et al 1996), hydrothermal (Lu et al 2001), spray pyrolysis (Lenggoro et al 2000), sol-gel (Lin et al 2000; Ahmadi et al 2000; Zhang et al 2001) techniques, etc has been successfully employed for synthesis of silicate based phosphor. This paper presents the preparation of $\mathrm{Eu}^{3+}$ activated calcium based silicate phosphors which is prepared by sol-gel technique and charac- 
terized by photoluminescence (PL), X-ray diffraction (XRD), differential thermal analysis (DTA) and scanning electron microscopy (SEM) techniques.

\section{Experimental}

Eu doped $\mathrm{CaSiO}_{3}$, (Ca, Ba) $\mathrm{SiO}_{3}$ and $(\mathrm{Ca}, \mathrm{Sr}) \mathrm{SiO}_{3}$ powders were prepared by sol-gel technique. Analar grade powder $\mathrm{CaCO}_{3}$, tetra ethyl orthosilicate $\left[\mathrm{Si}\left(\mathrm{OC}_{2} \mathrm{H}_{5}\right)_{4}\right] /$ $\mathrm{CaCO}_{3}, \mathrm{Si}\left(\mathrm{OC}_{2} \mathrm{H}_{5}\right)_{4}, \mathrm{BaCO}_{3} / \mathrm{CaCO}_{3}, \mathrm{Si}\left(\mathrm{OC}_{2} \mathrm{H}_{5}\right)_{4}, \mathrm{SrCO}_{3}$ were taken as starting materials for the preparation of $\mathrm{CaSiO}_{3},(\mathrm{Ca}, \mathrm{Ba}) \mathrm{SiO}_{3}$ and $(\mathrm{Ca}, \mathrm{Sr}) \mathrm{SiO}_{3}$, respectively in required proportion. For the preparation of doped sample known amount of impurity $\mathrm{Eu}_{2} \mathrm{O}_{3}$ was added to starting materials. $\mathrm{CaCO}_{3}, \mathrm{BaCO}_{3} / \mathrm{CaCO}_{3}, \mathrm{SrCO}_{3}$ were first dissolved in dilute nitric acid. Later on ethanol and double distilled water in the proportion of $2: 1$, were added to the above transparent nitrate solution. Subsequently ethyl orthosilicate was added to this solution in small instalments and stirred well. $\mathrm{Ca} /(\mathrm{Ca}, \mathrm{Ba}) /(\mathrm{Ca}, \mathrm{Sr})$ nitrated and ethyl orthosilicate are soluble in ethanol. Diluted ammonia was added to the above solution that neutralizes the excess nitrate and results in the formation of gel. The gel thus formed was dried in air atmosphere for about 3-4 h at $100^{\circ} \mathrm{C}$, calcined at 300 and $600^{\circ} \mathrm{C}$ for $3 \mathrm{~h}$ and then quenched to room temperature and then crushed to fine powder for further work.

Formation of silicate was confirmed by studying XRD pattern. Differential thermal analysis (DTA) was used to find the crystallization temperature of silicates. The surface morphology was investigated using SEM analysis. Photoluminescence spectrum was recorded on Jobin Yvon Spectroflurometer at room temperature.

\section{Results and discussion}

\subsection{DTA measurement}

Figure 1 shows the differential thermal analysis (DTA) curve of $\mathrm{Eu}$ doped $\mathrm{CaSiO}_{3}$ powder. The DTA endothermic peak between temperature 200 and $325^{\circ} \mathrm{C}$ is attributed to the elimination of residual solvents. The second endothermic peak between 325 and $600^{\circ} \mathrm{C}$ is due to elimination of the organic compounds. The small exothermic effect around $850-875^{\circ} \mathrm{C}$ on the DTA curve can be attributed to crystallization of the $\mathrm{CaSiO}_{3}$. Annealing at lower temperature may result in the formation of $\mathrm{Ca}_{2} \mathrm{SiO}_{4}$. The optimum firing temperature for crystallization was around $850-875^{\circ} \mathrm{C}$ that was confirmed by DTA measurement. These results are consistent with the results reported by Fan et al (1996).

\subsection{XRD measurement}

X-ray diffraction (XRD) pattern of doped silicate gel fired at $850^{\circ} \mathrm{C}$ is shown in figure 2 . The observed pattern matched with the standard data of the compound (JCPDS file no. 27-88). $\mathrm{CaSiO}_{3}$ monoclinic phase is present in large abundance along with small trace of $\mathrm{Ca}_{2} \mathrm{SiO}_{4}$ as orthorhombic phase. The crystal field symmetry and hence the effect of field on the shifting of emission lines is strongly dependent on the relative contents of these two phases. The following experiments are performed to study this effect.

\subsection{SEM analysis}

Particle size of phosphor plays an important role in deciding the luminescence quality of the material. Uniform particle size distribution and fine particles $(<5 \mu \mathrm{m})$ are some of the requirements of good luminescent materials. Figure 3 shows the SEM microphotograph of $(\mathrm{Ca}, \mathrm{Ba})$ $\mathrm{SiO}_{3}: \mathrm{Eu}^{3+}$ phosphor. Average particles of phosphor with less than $3 \mu \mathrm{m}$ is a good sign of lamp phosphor for coating purpose. SEM photograph of $(\mathrm{Ca}, \mathrm{Sr}) \mathrm{SiO}_{3}: \mathrm{Eu}^{3+}$ also shows similar results, except that some changes in particle size was observed, therefore are not shown here.

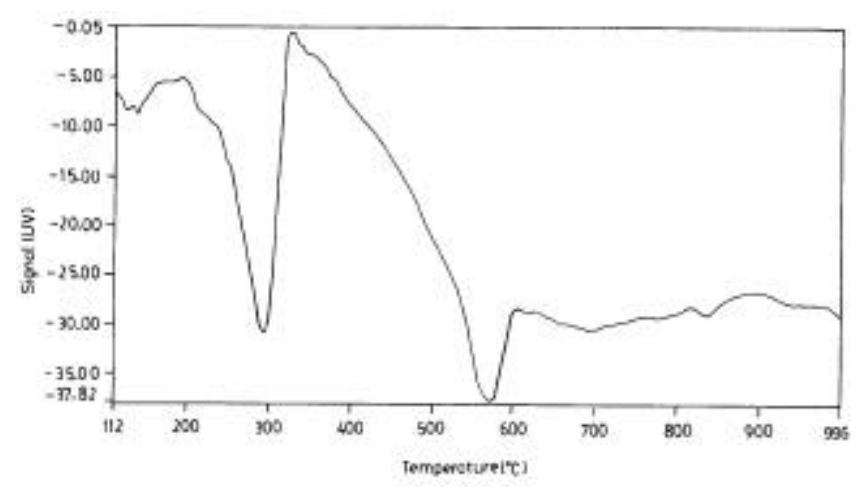

Figure 1. DTA curve for $\mathrm{CaSiO}_{3}: \mathrm{Eu}^{3+}$ gel.

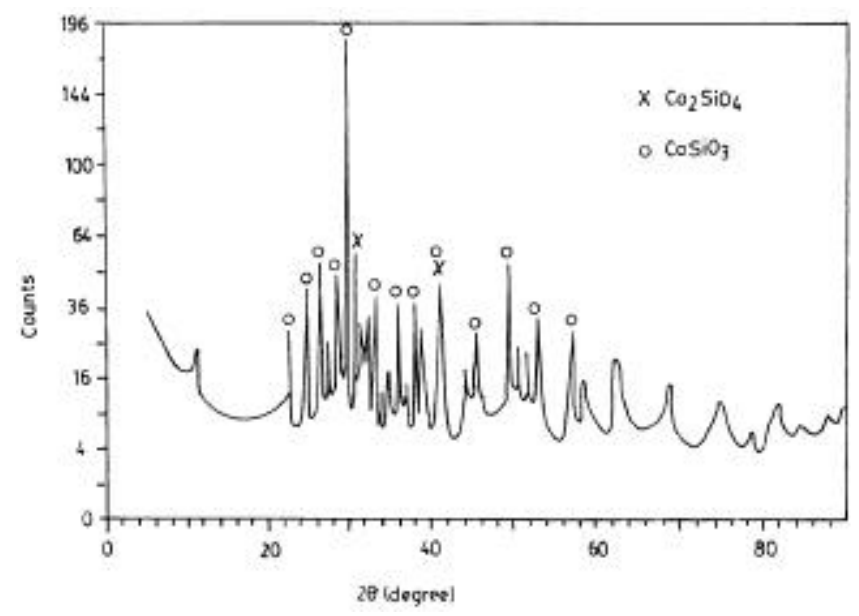

Figure 2. XRD pattern of $\mathrm{CaSiO}_{3}: \mathrm{Eu}^{3+}$ gel fired at $850^{\circ} \mathrm{C}$. 


\subsection{PL measurements}

3.4a $\mathrm{PL}$ in $\mathrm{CaSiO}_{3}: \mathrm{Eu}$ : Figure 4 shows the influence of firing temperature on the luminescence of $\mathrm{CaSiO}_{3}: \mathrm{Eu}^{3+}$ (3 mol\%), excited at $399 \mathrm{~nm}$. In a gel fired at $750^{\circ} \mathrm{C}$, prominent peaks are at 594 and $618 \mathrm{~nm}$ besides a weak shoulder at $660 \mathrm{~nm}$ due to transitions: ${ }^{5} D_{0} \rightarrow{ }^{7} F_{1},{ }^{5} D_{0} \rightarrow$ ${ }^{7} F_{2}$ and ${ }^{5} D_{0} \rightarrow{ }^{7} F_{3}$, respectively. The splitting of weak 618 line into two components was also observed. As the firing temperature is raised to $850^{\circ} \mathrm{C}$, emission lines become strong. The $594 \mathrm{~nm}$ line due to ${ }^{5} D_{0} \rightarrow{ }^{7} F_{1}$ is split into two components at 594 and $599 \mathrm{~nm}$, whereas no appreciable splitting is observed for $618 \mathrm{~nm}$ line. The intensity of $618 \mathrm{~nm}$ line is three times more than $594 \mathrm{~nm}$ line. Further increase in firing temperature to $950^{\circ} \mathrm{C}$, resulted in decrease in emission intensity of all lines due to the variation of interaction between $\mathrm{Eu}^{3+}$ and $\mathrm{O}^{2-}$ ions at higher temperature. The main band splits into three bands, 616, 620 and $622 \mathrm{~nm}$, and the band corresponding to ${ }^{5} D_{0} \rightarrow{ }^{7} F_{1}$ transition split into 590 and $597 \mathrm{~nm}$. Due to strong interaction between $\mathrm{Eu}^{3+}$ and $\mathrm{O}^{2-}$ ions in fired gel, appreciable splitting of emission lines can be observed by the crystal field. The splitting of energy levels by crystal field is dependent on the symmetry of the field and relates to surroundings of $\mathrm{Eu}^{3+}$ ions in the crystal lattice. When $\mathrm{Eu}^{3+}$ ion is put into the $\mathrm{Ca}^{2+}$ site, which is coordinated by six $\mathrm{O}^{2^{-}}$ions, the splitting of energy levels by crystal field would change with the position of $\mathrm{Eu}^{3+}$ ion in the crystal lattice. Along with $\mathrm{CaSiO}_{3}$, small amount of $\mathrm{Ca}_{2} \mathrm{SiO}_{4}$ phase is formed during firing experiments. The splitting of energy levels depends on the relative contents of $\mathrm{CaSiO}_{3}$ and $\mathrm{Ca}_{2} \mathrm{SiO}_{4}$ in fired gel. In samples fired at $850^{\circ} \mathrm{C}$, practically no splitting of $618 \mathrm{~nm}$ main peak was observed. It seems that relative concentration of $\mathrm{CaSiO}_{3}$ phase is highest and $\mathrm{Eu}^{3+}$ may be surrounded by same environment in this sample. $\mathrm{Eu}^{3+}$ emission usually occurs from ${ }^{5} D_{0} \rightarrow{ }^{7} F_{j}$ transitions. There are three transitions, which are of prime importance: ${ }^{5} D_{0} \rightarrow{ }^{7} F_{0}$ (around $570 \mathrm{~nm}$ ), ${ }^{5} D_{0} \rightarrow{ }^{7} F_{1}$ (around $594 \mathrm{~nm}$ ) and ${ }^{5} D_{0} \rightarrow{ }^{7} F_{2}$ (around $610-630 \mathrm{~nm}$ ). The first one is strongly forbidden transition and yet observed with appreciable intensity in some hold. The ${ }^{5} D_{0} \rightarrow{ }^{7} F_{1}$ transition is allowed as magnetic dipole transition. This is the only transition when $\mathrm{Eu}^{3+}$ is situated at a site coinciding with a centre of symmetry. ${ }^{5} D_{0} \rightarrow{ }^{7} F_{2}$ allowed as forced electric dipole transition and is induced when $\mathrm{Eu}^{3+}$ is situated at a site which lacks the inversion symmetry. This transition is much stronger than that of the transition to ${ }^{7} F_{1}$ state. Further, all the lines corresponding to these transition split into number of components decided by the local symmetry.

Excitation spectrum of $\mathrm{CaSiO}_{3}: \mathrm{Eu}^{3+}(3 \mathrm{~mol} \%)$ shows two lines at 267 and $399 \mathrm{~nm}$, monitored at $618 \mathrm{~nm}$ (results are not reproduced here). The emission spectra for 267 and $399 \mathrm{~nm}$ excitations are shown in figure 5. For $399 \mathrm{~nm}$ excitation two peaks are obtained around the wavelength 594 and $618 \mathrm{~nm}$ due to ${ }^{5} D_{0} \rightarrow{ }^{7} F_{1}$ and ${ }^{5} D_{0}$ $\rightarrow{ }^{7} F_{2}$ transitions, respectively as described earlier (curve a). Small peak around $660 \mathrm{~nm}$ is also obtained due to ${ }^{5} D_{0} \rightarrow{ }^{7} F_{3}$ transition. The intensity of $618 \mathrm{~nm}$ peak is almost three times more than $594 \mathrm{~nm}$ peak. When the sample is excited by $399 \mathrm{~nm}$ wavelength, $\mathrm{Eu}^{3+}$ ion is raised to ${ }^{5} L_{6}$ level from ground state. During emission, $\mathrm{Eu}^{3+}$ ion decays stepwise from ${ }^{5} L_{6}$ to ${ }^{5} D_{0}$ level. Since the separation between ${ }^{5} D_{0}$ and ${ }^{7} F_{j}$ (where $j=0,1,2,3,4,5$ and 6) is large, the stepwise decay process stops here and returns to ground state by giving emission in the orange and red regions. If the impurity ion does not occupy centre of symmetry of the crystal lattice, then it will give both magnetic and electric dipole transitions (Oomen and van Dongen 1989). When the rare earth impurity ion is located at the centre of symmetry in the relevant crystal

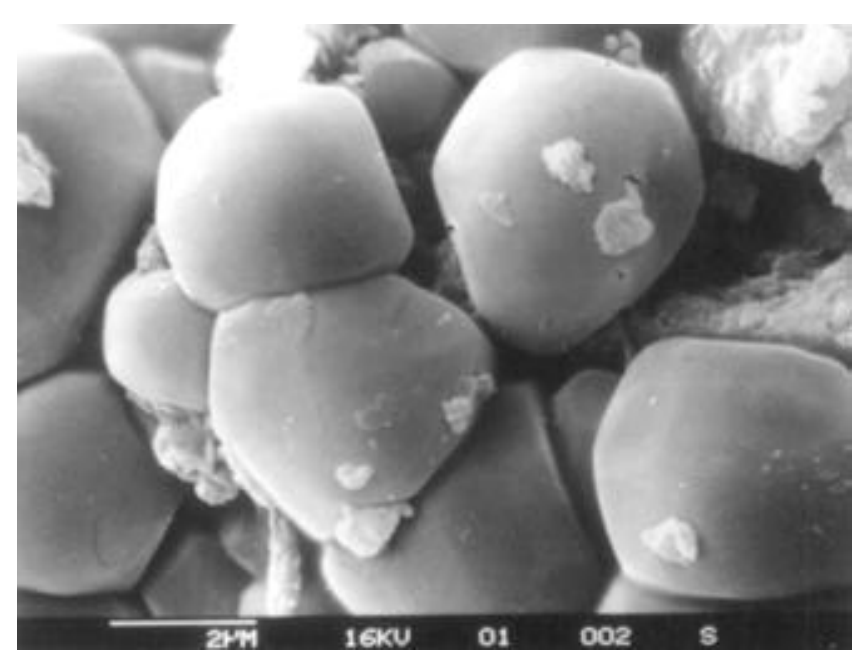

Figure 3. SEM microphotograph $(\times 10,000)$ of $(\mathrm{Ca}, \mathrm{Ba}) \mathrm{SiO}_{3}$ : $\mathrm{Eu}^{3+}$ phosphor.

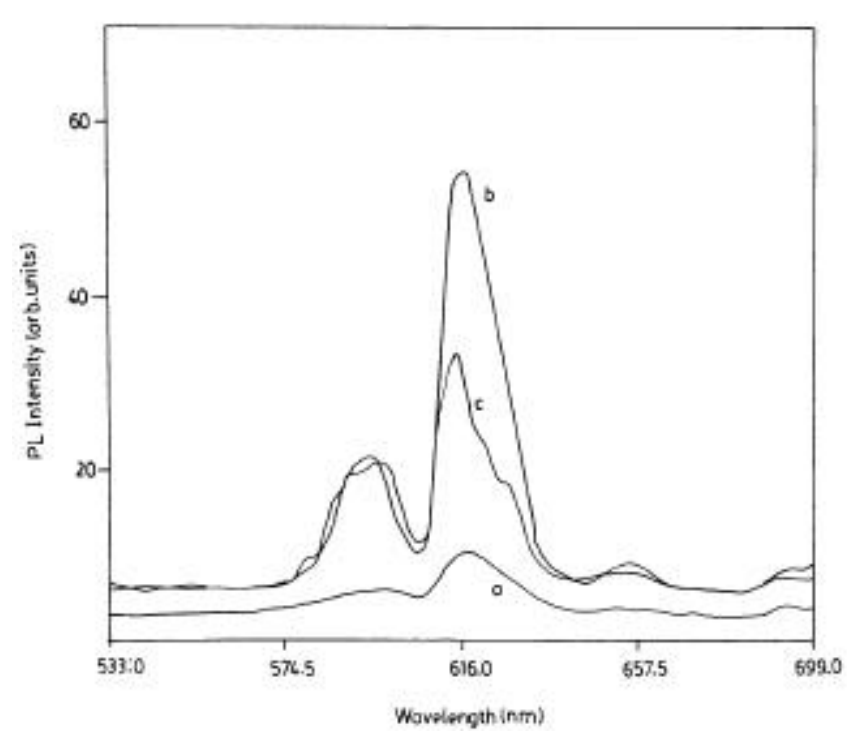

Figure 4. Photoluminescence emission spectra of the $\mathrm{CaSiO}_{3}$ : $\mathrm{Eu}^{3+}$ gel fired at a. $750^{\circ} \mathrm{C}$, b. $850^{\circ} \mathrm{C}$, and c. $950^{\circ} \mathrm{C}$. 
lattice, only magnetic dipole transitions are allowed. In the present case both magnetic and forced electric dipole transitions, ${ }^{5} D_{0} \rightarrow{ }^{7} F_{1}$ and ${ }^{5} D_{0} \rightarrow{ }^{7} F_{2}$ emission lines, respectively are observed. The forced electric dipole transitions arise from the lack of a centre of symmetry. The emission in the vicinity of $600 \mathrm{~nm}$ is due to the magnetic dipole transition ${ }^{5} D_{0} \rightarrow{ }^{7} F_{1}$, which is insensitive to the site symmetry. The emission around $610-630 \mathrm{~nm}$ is due to the electric dipole transition of ${ }^{5} D_{0} \rightarrow{ }^{7} F_{2}$, induced by the lack of inversion symmetry at the $\mathrm{Eu}^{3+}$ site, is much stronger than that of the transition to the ${ }^{7} F_{1}$ state. Luminescence of $\mathrm{Eu}^{3+}$ ions in commercial red phosphors such as $\mathrm{YVO}_{4}, \mathrm{Y}_{2} \mathrm{O}_{3}$ and $\mathrm{Y}_{2} \mathrm{O}_{2} \mathrm{~S}$, occupy the site that has no inversion of symmetry. The strong emission due to the electric dipole transition $\left({ }^{5} D_{0} \rightarrow{ }^{7} F_{2}\right)$ in the materials is utilized for practical applications. If the $\mathrm{Eu}^{3+}$ site has inversion symmetry, as in $\mathrm{Ba}_{2} \mathrm{GdNbO}_{5}, \mathrm{NaLuO}_{2}$ (Blasse and Bril 1970) and $\mathrm{InBO}_{3}$ (Avella et al 1967), the electrical dipole emission is weak, and the magnetic dipole transition becomes relatively stronger and dominating. In $\mathrm{ABaGd}_{0.5}\left(\mathrm{PO}_{4}\right)_{2}: \mathrm{Eu}_{0.5}^{3+}$ (where $\mathrm{A}=\mathrm{Li}, \mathrm{Na}$, and $\mathrm{K}$ ), emission lines for magnetic $\left({ }^{5} D_{0} \rightarrow{ }^{7} F_{1}\right)$ and forced electric dipole transitions $\left({ }^{5} D_{0} \rightarrow{ }^{7} F_{2}\right)$ were observed (Band et al 1999). These are consistent with the earlier reported results (Oomen and van Dongen 1989). The ${ }^{5} D_{0} \rightarrow{ }^{7} F_{2}$ transition is dependent upon the local symmetry, whereas ${ }^{5} D_{0} \rightarrow{ }^{7} F_{1}$ emission may be related to local symmetry due to insensitivity to the site symmetry. Since ${ }^{5} D_{0} \rightarrow{ }^{7} F_{2}$ transition is much stronger than that of the ${ }^{5} D_{0} \rightarrow{ }^{7} F_{1}$ transition, the $\mathrm{Eu}^{3+}$ ion in the calcium silicate prepared by the sol-gel process is situated at the low symmetry sites. The other allowed weak transitions (low intensity) are ${ }^{5} D_{0} \rightarrow{ }^{7} F_{0},{ }^{5} D_{0} \rightarrow{ }^{7} F_{3}$, and ${ }^{5} D_{0} \rightarrow{ }^{7} F_{4}$. Figure 5 (curve b) shows the emission spectrum of doped silicate excited at $267 \mathrm{~nm}$ wavelength. Like $399 \mathrm{~nm}$ excitation wavelength, prominent peaks are observed at 594 and $618 \mathrm{~nm}$ along with a shoulder at $660 \mathrm{~nm}$. The overall emission intensity is drastically reduced. The $267 \mathrm{~nm}$ excitation wavelength may correspond to $\mathrm{O}^{2-}$ ions. Earlier it has been reported that the charge transfer from ligands $\left(\mathrm{O}^{2-}\right.$ ions $)$ to $\mathrm{Eu}^{3+}$ ions would play an important role on the excitation and emission bands of $\mathrm{Eu}^{3+}$ ions in fired $\mathrm{MgSiO}_{3}$ gel (Fan et al 1996). However, maximum emission output was obtained for $399 \mathrm{~nm}$ excitation wavelength in fired $\mathrm{CaSiO}_{3}: \mathrm{Eu}^{3+}$ gel. Therefore, $399 \mathrm{~nm}$ wavelength is used for excitation instead of $267 \mathrm{~nm}$. The inset of figure 5 shows the variations of $618 \mathrm{~nm}$ peak intensity with the $\mathrm{Eu}^{3+}$ concentration in calcium silicate gel for $399 \mathrm{~nm}$ excitation wavelength. Experimental photoluminescence intensity was plotted against the concentration. Results show that the $\mathrm{Eu}^{3+}$ emission intensity increases in the beginning up to $3 \mathrm{~mol} \%$ and starts decreasing slowly for higher concentration. This may be due to the concentration quenching of $\mathrm{Eu}^{3+}$ emission.

In doped $\mathrm{CaSiO}_{3}, \mathrm{Eu}^{3+}$ ion enters into $\mathrm{Ca}^{2+}$ lattice site. The ionic radii of $\mathrm{Eu}^{3+}$ and $\mathrm{Ca}^{2+}$ are 0.113 and $0.106 \mathrm{~nm}$, respectively. Since ionic radius of $\mathrm{Ca}^{2+}$ is smaller than $\mathrm{Eu}^{3+}, \mathrm{CaSiO}_{3}$ host could accommodate only small percentage of impurity ions. Moreover, there is charge imbalance in the host lattice due to doping of trivalent $\mathrm{Eu}^{3+}$ cations. In a gel with impurity concentration above $3 \mathrm{~mol} \% \mathrm{Eu}^{3+}$ ions go to the interstitial sites. This may trap emitted light, resulting into decrease of intensity.

3.4b $\mathrm{PL}$ in ( $\mathrm{Ca}, \mathrm{Ba}$ ) $\mathrm{SiO}_{3}: \mathrm{Eu}^{3+}$ and ( $\left.\mathrm{Ca}, \mathrm{Sr}\right) \mathrm{SiO}_{3}: \mathrm{Eu}^{3+}$ : The excitation spectra of $(\mathrm{Ca}, \mathrm{Ba}) \mathrm{SiO}_{3}: \mathrm{Eu}^{3+}(3 \mathrm{~mol} \%)$, monitored at $614 \mathrm{~nm}$ is shown in figure 6 (curve a). The

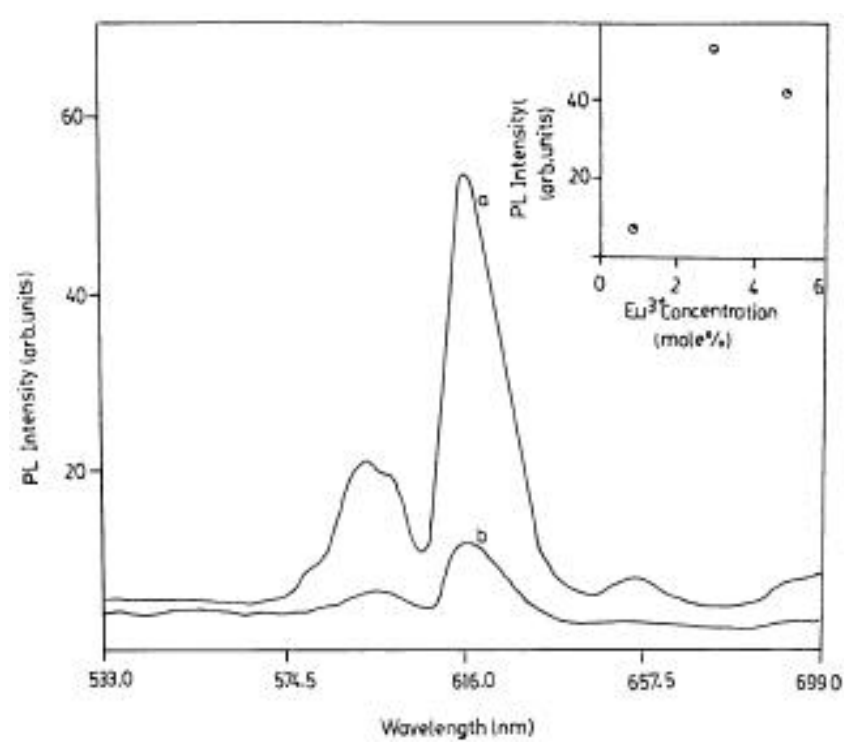

Figure 5. Photoluminescence emission spectrum of $\mathrm{CaSiO}_{3}$ : $\mathrm{Eu}^{3+}$ gel fired at $850^{\circ} \mathrm{C}$ : a. excited at $399 \mathrm{~nm}$ and b. excited at $267 \mathrm{~nm}$ wavelength. (Inset shows the variation of emission peak intensity at $618 \mathrm{~nm}$ with $\mathrm{Eu}^{3+}$ ion concentration).

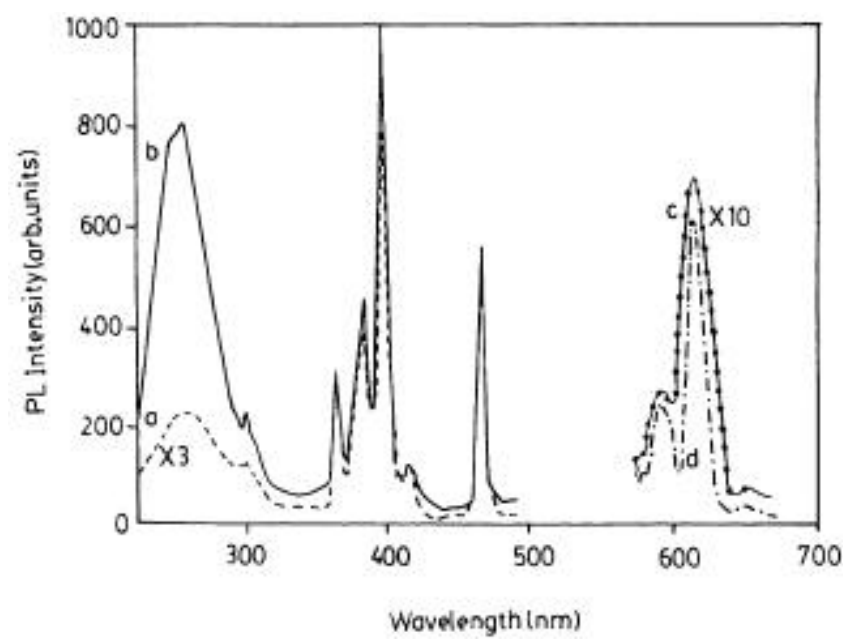

Figure 6. Photoluminescence spectrum of (a) excitation spectrum $\left(\lambda_{\text {em }}=614 \mathrm{~nm}\right)$ of $(\mathrm{Ca}, \mathrm{Ba}) \mathrm{SiO}_{3}: \mathrm{Eu}$, (b) excitation spectrum $\left(\lambda_{\mathrm{em}}=614 \mathrm{~nm}\right)$ of $(\mathrm{Ca}, \mathrm{Sr}) \mathrm{SiO}_{3}: \mathrm{Eu},(\mathrm{c})$ emission spectrum $\left(\lambda_{\text {ex }}=254 \mathrm{~nm}\right)$ of $(\mathrm{Ca}, \mathrm{Ba}) \mathrm{SiO}_{3}:$ Eu and (d) emission spectrum $\left(\lambda_{\mathrm{ex}}=254 \mathrm{~nm}\right)$ of $(\mathrm{Ca}, \mathrm{Sr}) \mathrm{SiO}_{3}: \mathrm{Eu}$. 
broad band was observed at $254 \mathrm{~nm}$. Besides charge transfer bands are observed at $392 \mathrm{~nm}$. The excitation of $\mathrm{Eu}^{3+}$ takes place from the bottom of the ${ }^{7} F_{0}$ curve, rising along the straight vertical, until it crosses the charge-transfer state (CTS). Relaxation occurs along the CTS curve. Near the bottom of CTS curve, the excitation is transferred to ${ }^{5} D_{j}$ states. Relaxation to the bottom of the ${ }^{5} D_{j}$ states is followed by light emission downward to ${ }^{7} F_{j}$ states. This model can explain the following experimental findings: (i) No luminescence is found from ${ }^{5} D_{3}$ in $\mathrm{Y}_{2} \mathrm{O}_{2} \mathrm{~S}$ : $\mathrm{Eu}^{3+}$, (ii) the luminescence efficiency is higher for phosphors with higher CTS energy (Blasse 1966) and (iii) the quenching temperature of the luminescence from ${ }^{5} D_{j}$ is higher as $j(0,1,2,3)$ decreases. The excited $4 f$ states may dissociate into an electron-hole pair.

By taking a model where CTS is a combination of $4 f^{7}$ electron plus a hole, one finds that the resulting spin multiplicities should be 7 and 9 . It is the former state that affects optical properties related to the ${ }^{7} F_{j}$ state by spinrestricted covalency. The intensity ratio of the luminescence from ${ }^{5} D_{0} \rightarrow{ }^{7} F_{2}$ and from ${ }^{5} D_{0} \rightarrow{ }^{7} F_{1}$ decreases with increasing CTS energy sequentially as $\mathrm{ScVO}_{4}, \mathrm{YVO}_{4}$, $\mathrm{ScPO}_{4}$, and $\mathrm{YPO}_{4}$, all of which have the same type of zircon structure (Blasse and Bril 1969). The above intensity ratio is small in $\mathrm{YF}_{3}: \mathrm{Eu}^{3+}$ even though $\mathrm{Eu}^{3+}$ occupies a site without inversion symmetry (Blasse and Bril 1967). It is to be noted that CTS in fluoride have higher energies than those in oxides. The results suggest that higher CTS energies reduce the strength of the electric dipole transition ${ }^{5} D_{0} \rightarrow{ }^{7} F_{2}$ in $\mathrm{Eu}^{3+}$. In CTS, electrons in the neighbouring anions are transferred as $4 f$ orbitals and results in strong optical absorptions. Optical absorption due to a charge transfer transition are found in $\mathrm{Eu}^{3+}$. CTS absorptions in $\mathrm{Eu}^{3+}$ and $\mathrm{Yb}^{3+}$ have energies less than $40 \times$ $10^{3} \mathrm{~cm}^{-1}$. They can, therefore, interact with $4 f$ levels, leading to $f \rightarrow f$ emissions.

One can conclude that those ions that are easily oxidized to the tetravalent state have lower $4 f \rightarrow 5 d$ transition energies, while those that are easily reduceable to the divalent state have lower CTS transition energies. It has been confirmed that $4 f^{0}, 4 f^{7}$ and $4 f^{14}$ electron configurations are relatively stable. The optical absorption transition at $254 \mathrm{~nm}$ may be related to $\mathrm{Eu}^{3+}$, due to the $4 f$ shell. The transition corresponding to wavelength 254 is ${ }^{7} F_{0} \rightarrow{ }^{5} L_{6}$. The fluorescence lamp is a low pressure mercury discharge lamp with a layer of phosphor particles on the inside surface of a glass tube. The internal radiation which is generated, mostly at $254 \mathrm{~nm}(85 \%)$ is the resonance wavelength of the mercury vapour discharge. The other $15 \%$ are distributed among 185, 315, $365,430,546$ and $578.5 \mathrm{~nm}$. The $254 \mathrm{~nm}$ excitation wavelength in $(\mathrm{Ca}, \mathrm{Ba}) \mathrm{SiO}_{3}: \mathrm{Eu}^{3+}$ and $(\mathrm{Ca}, \mathrm{Sr}) \mathrm{SiO}_{3}: \mathrm{Eu}^{3+}$ is $100 \%$ overlapping to the main mercury discharge wavelength at $254 \mathrm{~nm}$. Therefore, the $254 \mathrm{~nm}$ wavelength was selected for the excitation in $(\mathrm{Ca}, \mathrm{Ba}) \mathrm{SiO}_{3}: \mathrm{Eu}^{3+}$ and (Ca, Sr) $\mathrm{SiO}_{3}: \mathrm{Eu}^{3+}$ instead of 388, 392 and $465 \mathrm{~nm}$. The emission spectra of (Ca, $\mathrm{Ba}) \mathrm{SiO}_{3}: \mathrm{Eu}^{3+}(3 \mathrm{~mol} \%)$ is shown in figure 6 (curve c). The strong emission peak observed at the wavelength $614 \mathrm{~nm}$, excited by $254 \mathrm{~nm}$ light, corresponding to ${ }^{5} D_{0} \rightarrow{ }^{7} F_{2}$ transition. Weak peak observed at $594 \mathrm{~nm}$ is due to ${ }^{5} D_{0} \rightarrow{ }^{7} F_{1}$ transition. Strong ${ }^{5} D_{0} \rightarrow{ }^{7} F_{2}$ transition of $\mathrm{Eu}^{3+}$ observed in red region of the spectrum is very important for lamp phosphor application (excitation wavelength is $254 \mathrm{~nm}$ ).

When the sample is excited by $254 \mathrm{~nm}$ light, $\mathrm{Eu}^{3+}$ ion is raised to ${ }^{5} L_{6}$ from ground state. During emission, $\mathrm{Eu}^{3+}$ ion decays stepwise from ${ }^{5} L_{6}$ to ${ }^{5} D_{0}$ state giving small quanta of energy to the lattice; it decays non-radiatively between ${ }^{5} L_{6}$ to ${ }^{5} D_{0}$ state. Since the separation between ${ }^{5} D_{0}$ and ${ }^{7} F_{2}$ is large, the process of step-wise decay stops here and it returns to ground state by giving emission in red and orange $(594 \mathrm{~nm})$ regions of the spectrum. In the transition ${ }^{5} D_{0} \rightarrow{ }^{7} F_{2}$ emission, $J=2$ and it is an allowed transition. Being the impurity atom, $\mathrm{Eu}^{3+}$ does not occupy at the centre of symmetry. It will give both magnetic and electric dipole transition when $J=1$. However, when $J \leq$ 6 , where $J=2,4,6$ are allowed transitions, the electric dipole transitions are called forced electric dipole transitions. The transition ${ }^{5} D_{0} \rightarrow{ }^{7} F_{1}$ gives orange emission. If the $\mathrm{Eu}^{3+}$ ions are located at a site i.e. a centre of symmetry in the relevant crystal lattice, only magnetic dipole transitions are possible. The selection rule is $\Delta J=0, \pm 1$ of $\mathrm{Eu}^{3+}$ ions is situated at a centre of symmetry and is brought in ${ }^{5} D_{0}$ state, the only possible transition is ${ }^{5} D_{0} \rightarrow$ ${ }^{7} F_{1}$ corresponding to the wavelength $594 \mathrm{~nm}$. In another sample we have used $\mathrm{Sr}$ instead of $\mathrm{Ba}$ in several mixed silicate phosphor. In $(\mathrm{Ca}, \mathrm{Sr}) \mathrm{SiO}_{3}: \mathrm{Eu}^{3+}(3 \mathrm{~mol} \%)$ sample strong excitation peak is observed at $254 \mathrm{~nm}\left(\lambda_{\text {em }}=\right.$ $614 \mathrm{~nm}$ ) due to transition of ${ }^{7} F_{0} \rightarrow{ }^{5} L_{6}$ (figure 6 , curve b). The emission spectra of the sample is shown in figure 6 (curve d). It was observed that the strong emission peak observed at $614 \mathrm{~nm}\left(\lambda_{\text {ex }}=254 \mathrm{~nm}\right)$ is due to ${ }^{5} D_{0} \rightarrow{ }^{7} F_{2}$ transition of red region of the spectrum. In both the phosphors ${ }^{5} D_{0} \rightarrow{ }^{7} F_{2}$ transitions of $\mathrm{Eu}^{3+}$ (at $614 \mathrm{~nm}$ ) are intensely observed, hence $\mathrm{Eu}^{3+}$ ions enter at the centre of symmetry in the crystal lattice.

\section{Conclusions}

In conclusion, doped $\mathrm{CaSiO}_{3}$ is synthesized by sol-gel process and crystallization temperature appears at about $850-875^{\circ} \mathrm{C}$. Small trace of $\mathrm{Ca}_{2} \mathrm{SiO}_{4}$ is observed in $\mathrm{CaSiO}_{3}$ fired gel. The SEM results show uniform surface morphology of the phosphors and particle sizes are $<3 \mu \mathrm{m}$ and are very useful in coating purpose. $\mathrm{Eu}^{3+}$ emission lines are obtained at 594 and $618 \mathrm{~nm}$. All peaks split due to crystal field and splitting depends upon the firing temperature of the gel.

In $(\mathrm{Ca}, \mathrm{Ba}) \mathrm{SiO}_{3}: \mathrm{Eu}^{3+}$ and $(\mathrm{Ca}, \mathrm{Sr}) \mathrm{SiO}_{3}: \mathrm{Eu}^{3+}$, emission are observed at $614 \mathrm{~nm}$ when excited by $254 \mathrm{~nm}$. Emission of $\mathrm{Eu}^{3+}$ was found to be particularly useful as a red emitting lamp phosphor as it has good sensitivity and 
excitation overlapping is quite well with $254 \mathrm{~nm}$ of $\mathrm{Hg}$ emission. PL intensity of $614 \mathrm{~nm}$ peak is 10 times more in $(\mathrm{Ca}, \mathrm{Ba}) \mathrm{SiO}_{3}: \mathrm{Eu}^{3+}$ phosphor as compared to $(\mathrm{Ca}, \mathrm{Sr})$ $\mathrm{SiO}_{3}: \mathrm{Eu}^{3+}$ phosphor. Strong position of $\mathrm{Eu}^{3+}$ peak $(614$ $\mathrm{nm}$ ) indicates that $\mathrm{Eu}^{3+}$ ions are mostly present at the site of centre of symmetry of crystal lattice. Therefore, $(\mathrm{Ca}$, Ba) $\mathrm{SiO}_{3}: \mathrm{Eu}^{3+}$ phosphor may be used as an efficient red lamp phosphor.

\section{References}

Ahmadi T S, Haase M and Weller H 2000 Mater. Res. Bull. 35 1869

Avella F J, Sovers O J and Wiggins C S 1967 J. Electrochem. Soc. 114613

Band A M, Dhoble S J and Pode R B 1999 Bull. Mater. Sci. 22 965

Blasse G 1966 J. Chem. Phys. 452356

Blasse G 1970 J. Lumin. 1, 2766

Blasse G and Bril A 1967 Philips Res. Rep. 22481

Blasse G and Bril A 1969 J. Chem. Phys. 502974

Blasse G and Bril A 1970 Philips Tech. Rev. 31304

Cavouras D, Kandarakis I, Nomicos C D, Panayiotakis G S and Fezoulidis J 2000 Appl. Radiat. Isot. 32119

Cich M, Kim K, Choi H and Hwang T 1998 Appl. Phys. Lett. 732116

Crawford M K and Bixner L H 1991 J. Lumin. 48 \& 4937

Fan X, Wang M, Yu Yiu and Wu Q 1996 J. Phys. Chem. Solids 571259

Gomes De Mesquita A H and Bril A 1969a J. Electrochem. Soc. 116871

Gomes De Mesquita A H and Bril A 1969b Mater. Res. Bull. 4 643

Haft H H and Thornton W A 1972 JIES

Jain S, Gending J and Yuanfu H 1992 J. Mater. Sci. Lett. 11409

JCPDS (Joint Committee on Powder Diffraction Standards), Amer. Soc. for Testing Materials (PA) Card Number 27-88
Kandarakis I, Cavoures D, Prassopoulos P, Kanellopoulas E, Nomicos C D and Panayiotakis G S 1998 Appl. Phys. A67 521

Koedam M and Opstelten J J 1971 Light Res. Tech. 3205

Kurczyk H G and Wuhrer J 1971 Interceram. 2119

Lenggoro I W, Iskandar F, Mizushima H, Xia B, Okuyama K and Kijima N 2000 Jpn. J. Appl. Phys. Lett. 39 L1051

Leskela M and Niinitso L 1992 Mater. Chem. Phys. 317

Lin J, Sanger D U, Mennig M and Barner K 2000 Thin Solid Films $\mathbf{3 6 0} 39$

Lu S W, Copeland T, Lee B I, Tong W, Wasgner B K, Park W and Zhang F 2001 J. Phys. Chem. Solids 62777

Meijerink A and Blasse G 1989 J. Lumin. 43283

Moharil S V 1994 Bull. Mater. Sci. 1725

Ohnishi H 1983 Ann. Rev. Mater. Sci. 1983

Oomen E W J L and van Dongen A M A 1989 J. Non-Cryst. Solids 111205

Otvos N and Peto A 1998 Rad. Measur. 29319

Ouyang X, Kital A H and Xiao T 1996 J. Appl. Phys. 79 3229

Peters T E 1969 J. Electrochem. Soc. 116985

Pode R B and Dhoble S J 1997 Phys. Status Solidi(b) 203571

Rabinovich E M, Shmulovich J, Fratello V J and Kopylov N J 1987 Am. Ceram. Soc. Bull. 661505

Raue R, Vink A T and Welker T 1984 Philos. Tech. Rev. 44 335

Smets B M J 1987 Mater. Chem. Phys. 16283

Sohn K S, Cho B, Chang H, Park H D, Choi Y G and Kim K H 2000 J. Eur. Ceram. Soc. 201043

Su K, Tilley D T and Sailor M J 1996 J. Am. Ceram. Soc. 118 3459

Upadeo S V and Moharil S V 1996 Rad. Eff. Def. Solids 138 167

Wanmaker W L and ter Vrugt J W 1967 Philips. Res. Rep. 22 355

Wanmaker W L, Bril A, ter Vrugt J W and Broos J 1966 Philips Res. Rep. 21270

Welker T 1991 J. Lumin. 48 \& 4949

Zhang H X et al 2001 Mater. Chem. Phys. 6831 